Article

\title{
A Foundational Study for Normal F8-Containing Mouse Models for the miRNA Regulation of Hemophilia A: Identification and Analysis of Mouse miRNAs that Downregulate the Murine F8 Gene
}

\author{
Katarzyna I. Jankowska ${ }^{1}$, Maitreyi Chattopadhyay ${ }^{1,2}$, Zuben E. Sauna ${ }^{3}$ and \\ Chintamani D. Atreya ${ }^{1, *}$ \\ 1 OBRR/DBCD/LCH in the Center for Biologics Evaluation and Research, US Food and Drug Administration, \\ Silver Spring, MD 20993, USA; katarzyna.jankowska@fda.hhs.gov (K.I.J.); \\ maitreyi.chattopadhya@fda.hhs.gov (M.C.) \\ 2 OTAT//DCGT/GTB in the Center for Biologics Evaluation and Research, US Food and Drug Administration, \\ Silver Spring, MD 20993, USA \\ 3 OTAT/DPPT/HB in the Center for Biologics Evaluation and Research, US Food and Drug Administration, \\ Silver Spring, MD 20993, USA; zuben.sauna@fda.hhs.gov \\ * Correspondence: Chintamani.atreya@fda.hhs.gov
}

Received: 2 June 2020; Accepted: 30 July 2020; Published: 6 August 2020

\begin{abstract}
Hemophilia A (HA) is associated with defects in the $F 8$ gene, encoding coagulation factor VIII (FVIII). Our previous studies show that F8-targeting micro RNAs (miRNAs), a group of small RNAs involved in gene regulation, can downregulate F8 expression causing HA in individuals with normal F8-genotypes and increased HA severity in patients with mutations in F8. Understanding the mechanistic underpinnings of human genetic diseases caused or modulated by miRNAs require a small animal model, such as a mouse model. Here, we report a foundational study to develop such a model system. We identified the mouse $3^{\prime}$ untranslated region ( $3^{\prime} \mathrm{UTR}$ ) on murine F8-mRNA (muF8-mRNA) that can bind to murine miRNAs. We then selected three miRNAs for evaluation: miR-208a, miR-351 and miR-125a. We first demonstrate that these three miRNAs directly target the $3^{\prime} \mathrm{UTR}$ of muF8-mRNA and reduce the expression of a reporter gene (luciferase) mRNA fused to the muF8-3' UTR in mammalian cells. Furthermore, in mouse cells that endogenously express the $F 8$ gene and produce FVIII protein, the ectopic expression of these miRNAs downregulated $F 8$-mRNA and FVIII protein. These results provide proof-of-concept and reagents as a foundation for using a normal $F 8$-containing mouse as a model for the miRNA regulation of normal $F 8$ in causing or aggravating the genetic disease HA.
\end{abstract}

Keywords: microRNAs (miRNAs); bleeding disorders; coagulation factors; hemophilia A; mouse model

\section{Introduction}

Hemophilia A (HA) is an X-linked bleeding disorder mainly caused by defects in, or a deficiency of, blood coagulation factor VIII. Until recently, it was widely accepted that mutations in the coding sequence of the $F 8$ gene were the only cause of HA [1]. The mutation types in $F 8$ include missense, nonsense, synonymous, frameshift, splice site change, the deletion of single or multiple exons and inversions. However, there is no clear correlation between mutation types and HA severity, as the same mutation type (and sometimes the same mutation) is observed in individuals that are diagnosed with mild, moderate or severe HA [2]. More intriguingly, in $\sim 1 \%$ of severe and $\sim 3 \%$ of mild or moderate HA patients, no mutations in $F 8$ can be detected, clearly suggesting that there are other 
molecular mechanisms in addition to the mutations in $F 8$ that regulate FVIII expression [2,3]. We have previously demonstrated the microRNA-based posttranscriptional downregulation of $F 8$ [4-6] and that this mechanism is observed in HA patients with no defects in the F8 gene.

Micro RNAs are small, about 22 nucleotides, single-stranded RNAs that have been shown to exert their negative control on protein translation either at the initiation or elongation step by binding mainly to the $3^{\prime}$ untranslated region (3'UTR) of their target messenger RNAs [7].

Our previous studies for the first time provided experimental evidence by using HA patient samples that micro RNAs (miRNAs) can downregulate $F 8$ gene expression and this phenomenon was observed in HA subjects with no mutations in the $F 8$ gene [5].

Available preclinical animal models for HA (rats, dogs, sheep, and genetically engineered mice and pigs) are all centered around developing appropriate therapies for HA [8]. Only recently, we have shown that miRNAs can influence the HA disease outcomes, including in patients with the normal F8 gene [4-6]. To our knowledge, there are no animal models to test this hypothesis towards understanding the mechanistic details of miRNA mediated $F 8$ dysregulation. As a prerequisite to developing a suitable small animal model such as a mouse, in this report, we first identified the $3^{\prime}$ UTR of murine F8-mRNA and identified and characterized murine miRNAs that can bind to the muF8-mRNA and dysregulate FVIII expression, so that, based on these foundational studies, a normal F8-containing mouse could serve as an animal model for this line of investigations.

\section{Results}

\subsection{Prediction Analysis and MS2-Tagged Affinity Purification Assays Identify miRNAs Associated with Murine F8 3'UTR}

Like in humans, the murine $F 8$ gene is located on the $X$ chromosome. It spans about $200 \mathrm{~kb}$, and as such is one of the largest genes known. Its transcription yields a 7.5-kb mRNA product. Unlike the 3'UTR of human F8-mRNA, that has 1821 nucleotides, the muF8-mRNA has a very short 3'UTR region that is only 125-nucleotides [9]. Nevertheless, like in humans, the muF8 gene also comprises of 26 exons, which encode a polypeptide chain of 2319 amino acids (NP_032003) vs. 2351aa in humans (NP_000123)) and exhibit a similar domain structure [9]. We have previously shown that miRNAs are able to target human $F 83^{\prime}$ UTR and modulate $F 8$ expression [4,5]. What is interesting is that, in contrast to humans, mice rarely experience spontaneous bleeding episodes [8-11]; thus, this is an ideal system to evaluate the role of miRNAs in FVIII deficiency and HA.

To identify miRNAs that could potentially bind to the $3^{\prime} \mathrm{UTR}$ of muF8-mRNA, we used a bioinformatics approach. The software, miRanda (available at microRNA.org) identified six miRNAs that have a binding site in the 3'UTR of the muF8 (Figure 1a,b). Multiple software can predict miRNAs, and each have their own advantages and disadvantages; thus, we used multiple computational methods (miRanda, Target Scan, MiRDB, Diana Tools and mirWalk) and observed over $40 \%$ overlap between miRNAs identified using miRanda and Target Scan. The three other selected prediction methods (MiRDB, Diana Tools and mirWalk) showed no overlaps with miRanda or Target Scan and only about $20 \%$ overlap with each other (Figure 1 c).

As our results showing predictive software show, there is considerable diversity in computational predictions, and, thus, miRNAs identified need to be validated experimentally. Thus, an MS2-tagged affinity assay (MS2-TRAP) was performed in HEK293 cells as described previously [12-14]. We carried out this experiment by transfecting either MS2 vector alone (MS2-E, negative control) or MS2 fused to the 3'UTR of muF8 (MS2-muF8) in HEK293 cells. Using this approach, a pool of endogenous miRNAs associated with the $3^{\prime}$ UTR of muF8-mRNA were identified in HEK293 cells. The bound RNAs were then purified and specific miRNAs identified by next-generation sequencing (NGS). The NGS data were analyzed with the miRNA database, miRBase 21. Out of 2588 miRNAs scanned, 375 miRNAs were detected in the MS2 samples. In order to eliminate MS2-bound nonspecific miRNAs in MS2-E samples, we selected miRNAs that were detected with the total number of reads $\geq 40$. Out of the 375 miRNAs, 43 miRNAs met this criterion. To further distinguish miRNAs that are significantly different 
in MS2-E and MS2-muF8 samples, we calculated $p$-values using a t-test with degrees of freedom DF $=4$ and the assumption that standard deviation equals 8 reads counts. A threshold of $p$-value $<0.05$ was used to discriminate between significant and insignificant differences in the detection of miRNA. The data were further sorted by miRNAs fold change. Nine miRNAs displayed a 1.5-fold increases in MS2-muF8 (Table 1).

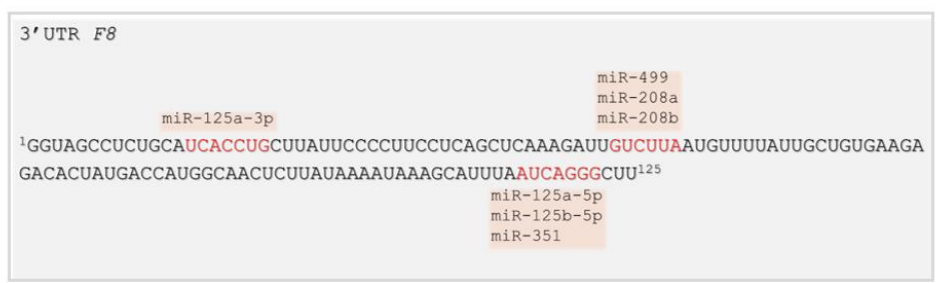

(a)

\begin{tabular}{|c|c|}
\hline 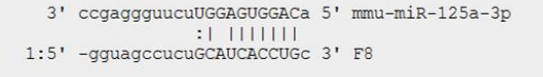 & $\begin{array}{ll}\text { mirSVR score: } & -0.8499 \\
\text { PhastCons score: } 0.5875\end{array}$ \\
\hline 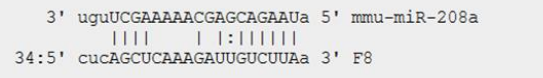 & $\begin{array}{l}\text { mirSVR score: } \quad-0.1164 \\
\text { PhastCons score: } 0.4842\end{array}$ \\
\hline 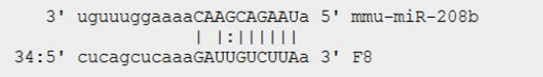 & $\begin{array}{ll}\text { mirSVR score: } & -0.1153 \\
\text { PhastCons score: } & 0.4842\end{array}$ \\
\hline 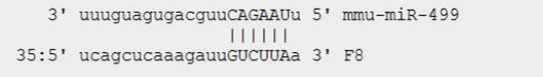 & $\begin{array}{l}\text { mirSVR score: } \quad-0.1130 \\
\text { PhastCons score: } 0.4842\end{array}$ \\
\hline 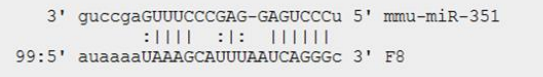 & $\begin{array}{l}\text { mirSVR score: } \quad-0.1421 \\
\text { PhastCons score: } 0.5000\end{array}$ \\
\hline $\begin{array}{l}\text { 3' aguguccaauuucccagAGUCCCU } 5^{\prime} \text { mmu-miR-125a-5p } \\
\text { IIIIII } \\
100: 5^{\prime} \text { uaaaauaaagcauuuaaUCAGGGC } \\
\text { ' }\end{array}$ & $\begin{array}{l}\text { mirSVR score: } \quad-0.1477 \\
\text { PhastCons score: } 0.5000\end{array}$ \\
\hline 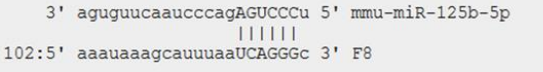 & $\begin{array}{l}\text { mirSVR score: } \quad-0.1463 \\
\text { PhastCons score: } 0.5000\end{array}$ \\
\hline
\end{tabular}

(b)

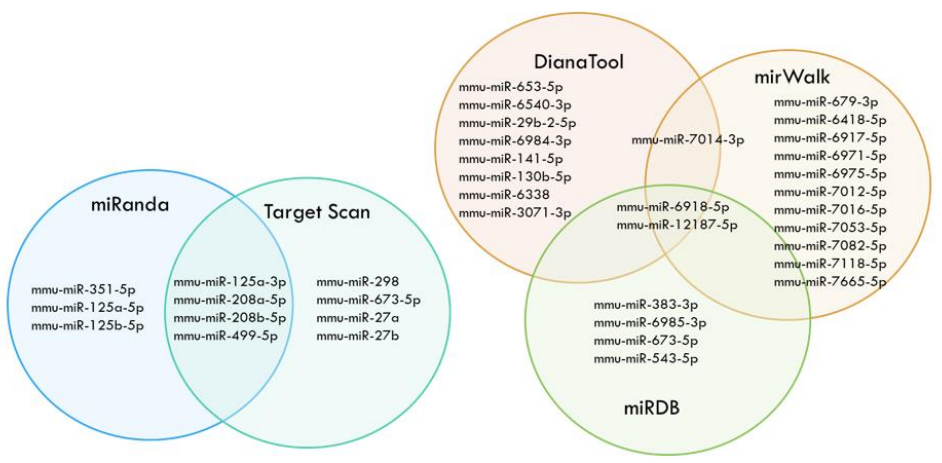

(c)

Figure 1. Target gene analysis. (a) mRNA sequence of murine $3^{\prime}$ untranslated region ( $3^{\prime} \mathrm{UTR}$ ) of the F8 region aligned with miRNAs that have potential target sites in $F 8$ highlighted by red font. (b) Sequence alignment of selected miRNAs and muF8-mRNA with potential target sites in the 3'UTR of muF8 predicted by miRanda (microrna.org). (c) Murine MiRNAs (mmu-miRNA) predicted to target muF 8 $3^{\prime}$ UTR by five different prediction algorithms (miRanda, Target Scan, MiRDB, Diana Tools and mirWalk) and displayed by Venn diagrams. 
Table 1. Micro RNAs (MiRNAs) identified in MS2-tagged RNA affinity assay. The list of 9 miRNAs detected in MS2-muF8 3'UTR sample with the highest fold change compared to the control (MS2-E) with a fold change of read counts $\geq 1.5$. The underlined miRNA was selected for further evaluation.

\begin{tabular}{ccccc}
\hline miRNA & Precursor & MS2-E & MS2-muF8 & Fold Change \\
\hline let-7a-5p & let-7a-1 & 222.0 & 343.0 & 1.55 \\
miR-93-5p & mir-93 & 189.0 & 305.0 & 1.61 \\
miR-196b-5p & mir-196b & 46.0 & 202.0 & 4.39 \\
miR-196a-5p & mir-196a-1 & 92.0 & 188.0 & 2.04 \\
miR-125a-5p & mir-125a & 97.0 & 150.0 & 1.55 \\
let-7f-5p & let-7f-1 & 55.0 & 147.0 & 2.67 \\
miR-30e-3p & mir-30e & 26.0 & 119.0 & 4.58 \\
miR-15b-3p & mir-15b & 31.0 & 83.0 & 2.68 \\
let-7g-5p & let-7g & 16.0 & 71.0 & 4.44 \\
\hline
\end{tabular}

\subsection{Predicted miRNAs Indeed Target Murine 3'UTR of F8-mRNA}

It is important to demonstrate that the miRNAs predicted to target muF8 3'UTR and pulled down in MS2-tagged affinity assay can indeed control the expression of FVIII protein. We selected three miRNAs, miR-208, miR-351 and miR-125a, that were identified in the pull-down assay as well as by in silico prediction, for detailed functional characterization.

In two human cell lines, HEK293 and HeLa, we evaluated whether murine miR-208a, miR-351 and miR-125a can regulate the murine $F 8$ gene $(\mathrm{muF})$ ) expression. Cells were co-transfected with luciferase reporter plasmid containing the $3^{\prime} \mathrm{UTR}$ of muF8 with plasmids expressing either miR-208a, miR-351, miR-125a or a scrambled miRNA expressing plasmid control (SC). In both cell lines, decreased luciferase expression (activity) was observed following the co-transfection of miR-208a, miR-351 or miR-125a but not in cells co-transfected with the control scrambled miRNA (Figure 2a). Expression of all three miRNAs, miR-208a, miR-351 or miR-125a, in the transfected cells was confirmed by Quantitative polymerase chain reaction (qPCR) analysis (Figure 2b). The reduction in luciferase activity in HEK 293 cells was approximately $60 \%, 40 \%$ and 20\% for miR-208a, miR-351 and miR-125a, respectively. The reduction in luciferase activity in HeLa cells was approximately $30 \%, 20 \%$ and $20 \%$ for miR-208a, miR-351 and miR-125a, respectively. The changes in luciferase activity were the highest in the presence of miR-208a in HEK293 cells (60\% decrease) and the lowest changes were observed for miR-125a ( $20 \%$ decrease). It should be noted that, while all tested miRNAs are endogenously expressed in HeLa and HEK293 cells (Figure 2c), the endogenous levels of miRNA-208a is much lower than that of miR-125a. High expression of miR-125a in both cell lines may be responsible for low and nonsignificant responses in HeLa and HEK293 cells, respectively, as endogenous expression may disturb and interfere with quantification of luciferase signal. 


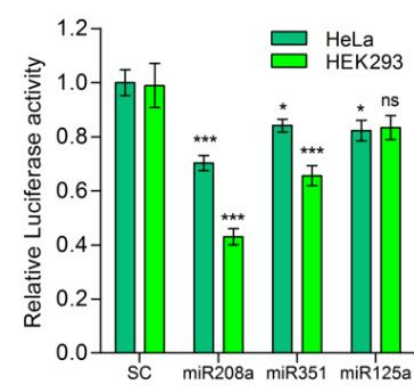

(a)

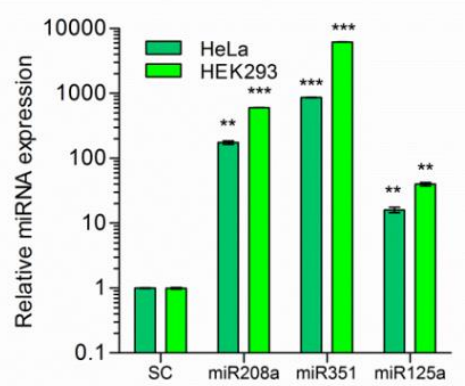

(b)

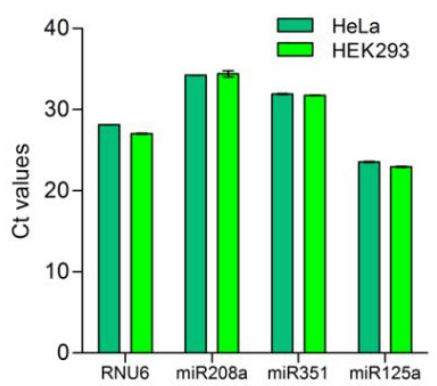

(c)

Figure 2. Predicted murine miRNAs indeed target $3^{\prime}$ UTR of murine F8-mRNA. (a) Relative luciferase activity in HeLa and HEK293 cells transfected with luciferase and miRNA expression vectors for miR-208a, miR-351 and miR-125a (HeLa: SC = $1.00 \pm 0.049, \mathrm{~N}=9 ; \operatorname{miR}-208 \mathrm{a}=0.7027 \pm 0.02843$, $\mathrm{N}=9$; miR-351 = 0.8413 $\pm 0.02369, \mathrm{~N}=9 ;$ miR-125a $=0.8222 \pm 0.03816, \mathrm{~N}=6$; HEK293: $\mathrm{SC}=0.9881 \pm 0.08065 \mathrm{~N}=8 . \mathrm{miR}-208 \mathrm{a}=0.4297 \pm 0.02946, \mathrm{~N}=11 ; \mathrm{miR}-351=0.6558 \pm 0.03693$, $\mathrm{N}=11$; miR-125a $=0.8339 \pm 0.04463, \mathrm{~N}=5$.). ( $\mathbf{b})$ Quantitative polymerase chain reaction (qPCR) analysis to determine the overexpression level of miRNAs $72 \mathrm{~h}$ after transfection (Mean \pm SEM for HeLa: $\mathrm{SC}=1.000 \pm 0.01171, \mathrm{~N}=3 ; \operatorname{miR}-208 \mathrm{a}=174.5 \pm 11.15 \mathrm{~N}=3 ; \operatorname{miR}-351=864.1 \pm 9.904 \mathrm{~N}=3$, miR-125a $=15.98 \pm 1.498, \mathrm{~N}=3$; HEK293: $\mathrm{SC}=1.000 \pm 0.02263, \mathrm{~N}=3 ; \mathrm{miR}-208 \mathrm{a}=599.8 \pm 1.916$, $\mathrm{N}=3$; miR-351 = $6183 \pm 10.04, \mathrm{~N}=3 ; \mathrm{miR}-208 \mathrm{a}=40.01 \pm 2.491 \mathrm{~N}=3$ ) and (c) Expression (Ct values) of endogenous miRNAs: miR-208a, miR-351 and miR-125 in HeLa and HEK293, relative to RNU6 (HeLa: RNU6 = 28.14 $\pm 0.015, \mathrm{~N}=3 ; \mathrm{miR}-208 \mathrm{a}=34.24 \pm 0.017, \mathrm{~N}=3 ; \mathrm{miR}-351=31.92 \pm 0.056, \mathrm{~N}=3$; miR-125a $=23.55 \pm 0.052, \mathrm{~N}=3$; HEK293: RNU6 $=27.06 \pm 0.058 \mathrm{~N}=3 . \mathrm{miR}-208 \mathrm{a}=34.40 \pm 0.37, \mathrm{~N}=3$; $\mathrm{miR}-351=31.76 \pm 0.033, \mathrm{~N}=3 ; \mathrm{miR}-125 \mathrm{a}=22.95 \pm 0.060, \mathrm{~N}=3) .{ }^{*} p<0.05^{* *} p<0.01,{ }^{* * *} p<0.001$; $\mathrm{SC}=$ Scrambled miRNA expressing plasmid control.

\subsection{MiR-208, miR-125a and miR-351 Target F8 3'UTR and Downregulate FVIII Expression in Mouse Cells}

Once the effect of downregulation by miR-208a, miR-351 or miR-125a on luciferase expression, when conjugated with $3^{\prime}$ UTR of $\mathrm{muF} 8$ was established, we determined whether the overexpression of tested miRNAs (1) suppresses the F8-mRNA levels in the cells or (2) exerts its effect on muF8 mRNA translational ability. Mouse MILE SVEN 1 cells (MS1 line) that endogenously express murine FVIII protein [15] were transfected individually with miR-208a, miR-351 or miR-125a expression plasmids and then muF8 mRNA levels were estimated by qPCR. As shown in Figure $3 \mathrm{a}, \mathrm{b}$, the overexpression of miR-208a, miR-351 and miR-125a significantly $(p=0.002)$ decreased muF8 mRNA levels. Concomitantly, the murine FVIII protein levels, as estimated by Western Blot analysis were also lowered by $25-70 \%$ following transfection of miR-208a, miR-351 or miR-125a expression plasmid, respectively, in MS1 cells (Figure 3c,d, Figure S1). These results demonstrate that the expression of miR-208a, miR-351 or miR-125a expression plasmid in mouse cells modulate murine FVIII protein expression. 


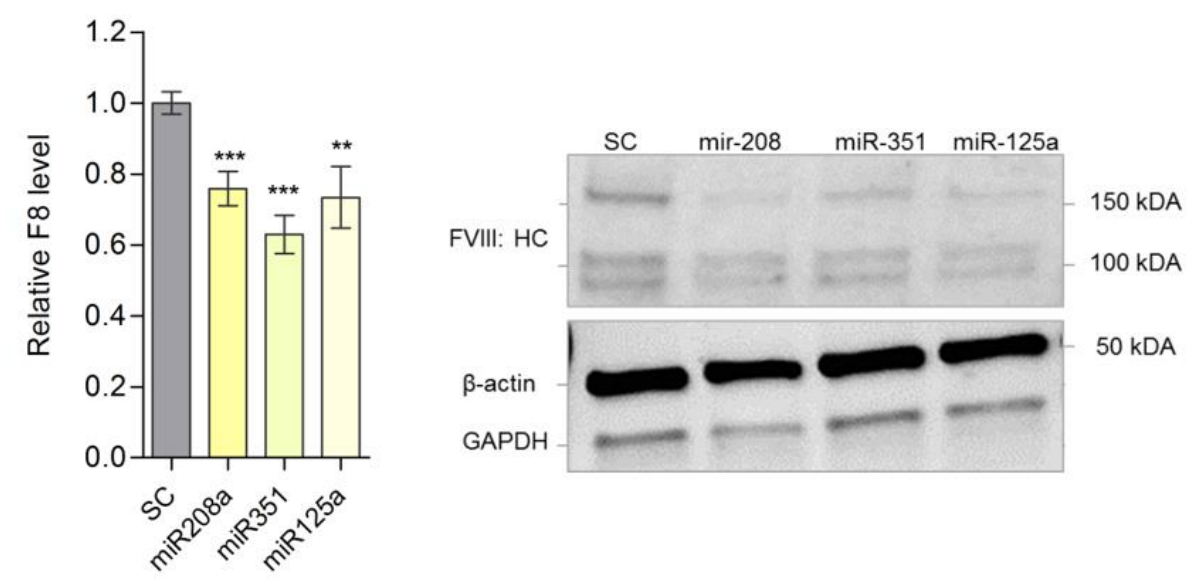

(a)

(c)

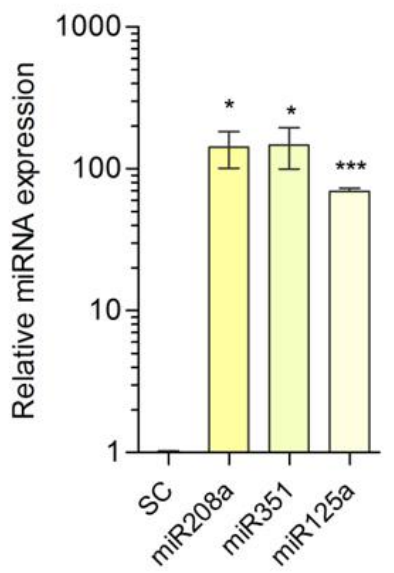

(b)

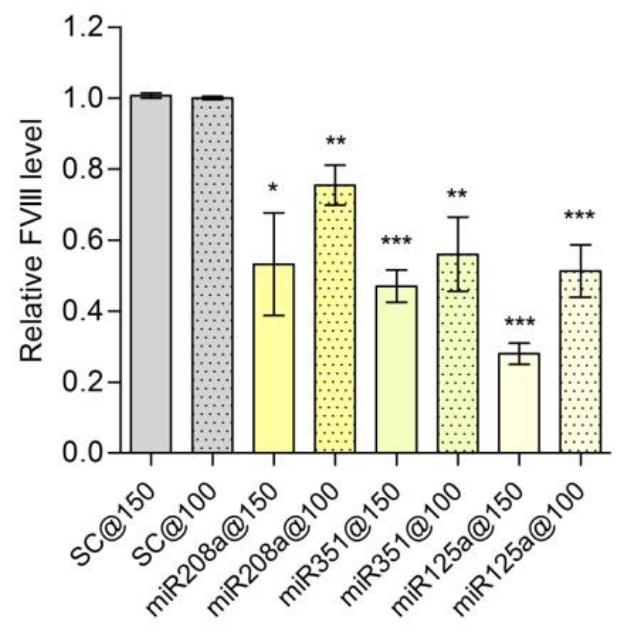

(d)

Figure 3. Predicted miRNAs can target $F 8$ and downregulate FVIII expression in MS1 cells. (a) Relative expression of $F 8$ mRNA ( $S C=0.9999 \pm 0.03159, \mathrm{~N}=19 ; \operatorname{miR}-208 \mathrm{a}=0.7589 \pm 0.04873, \mathrm{~N}=16$; miR-351 $=0.6299 \pm 0.05398, \mathrm{~N}=16 ; \mathrm{miR}-125 \mathrm{a}=0.7339 \pm 0.08668, \mathrm{~N}=16)$ and $(\mathbf{b})$ relative overexpression of miRNAs $(\mathrm{SC}=1.001 \pm 0.02631 \mathrm{~N}=4$; miR-208a $=141.5 \pm 40.66, \mathrm{~N}=4 ; \mathrm{miR}-351=146.9 \pm 47.05, \mathrm{~N}=4$; miR-125a $=69.41 \pm 3.856, \mathrm{~N}=4$.) in MS1 cells transfected with miRNAs expression vectors compared to control cells (SC). Q-PCR results of $F 8$ and miRNAs were normalized to Glyceraldehyde-3-Phosphate Dehydrogenase (GAPDH) and RNU6, respectively. (c) Relative FVIII level in MS1 cells collected $72 \mathrm{~h}$ after transfection with miRNAs: miR-208, miR-351 and miR-125a expression vectors compared to control cells (SC) determined by Western blot form transfected samples. Multiple species were detected: heavy chain polypeptides (HC) generated after FVIII single chain cleavage within the B domain with an apparent MW range between $90-200 \mathrm{kDa}$, light chain at about $100 \mathrm{kDa}$ and loading controls: $\beta$-actin and GAPDH detected at approximately 42 and $35 \mathrm{kDa}$, respectively. Full-length blots are presented in Supplementary Figure S1. (d) Quantification of FVIII heavy chain in cells transfected with miR-208 and miR-351and 125a with apparent MW of 150 kDa (@150) and 100 kDa (@100); (@100:SC = $1.000 \pm 0.004082$, $\mathrm{N}=4 ; \mathrm{miR}-208 \mathrm{a}=0.7545 \pm 0.056, \mathrm{~N}=4 ; \mathrm{miR}-351=0.560 \pm 0.104, \mathrm{~N}=4 ; \mathrm{miR}-125 \mathrm{a}=0.5123 \pm 0.07377$, $\mathrm{N}=4 ; @ 150: \mathrm{SC}=1.007 \pm 0.006667, \mathrm{~N}=3 ; \mathrm{miR}-208 \mathrm{a}=0.5320 \pm 0.1446, \mathrm{~N}=3 ; \mathrm{miR}-351=0.4700 \pm 0.04583$, $\mathrm{N}=3 ; \operatorname{miR}-125 \mathrm{a}=0.2800 \pm 0.0300, \mathrm{~N}=3$.) from $(\mathbf{c})$. Bands normalized to $\beta$-actin and GAPDH. ${ }^{*} p<0.05,{ }^{* *} p<0.01,{ }^{* * *} p<0.001$. 


\section{Discussion}

A growing body of research studies have highlighted the important role of miRNAs in hemostasis and thrombosis [16-19]. Our previous studies have also demonstrated the dysregulation of some miRNAs in blood samples of HA patients compared to healthy controls and their direct interaction with human F8-mRNA [4,5]. These studies were motivated by the unexplained phenomenon wherein some (albeit extremely rare) HA patients with a normal F8 gene (showing no mutations in the coding and non-coding regions) nonetheless express low amounts of FVIII and exhibit mild, moderate or severe forms of HA. In addition, our studies also provide an explanation for clinical reports showing that HA with the same mutation exhibit different levels of HA severity. We postulate that the miRNA-controlled expression of FVIII may secondarily influence FVIII levels of partially functional FVIII variants, thus aggravating the disease severity.

Here, we seek to lay the groundwork for more detailed mechanistic studies of miRNA mediated regulation of FVIII using in vivo mouse models. We therefore used prediction algorithms and an MS2-TRAP assay, to identify and characterize the miRNAs that potentially target and dysregulate murine FVIII (Figure 4). Detailed evaluation of three of these miRNAs were carried out in cell culture systems. We have shown that miR-125, miR-351 and miR-208 directly target the $3^{\prime} \mathrm{UTR}$ of muF8 and downregulate the muF8 gene and FVIII in a cell system. Our in vitro results clearly demonstrate that in mouse miRNAs can downregulate F8, much like what is observed in human HA patients. This should pave the way for studying HA and coagulation factor disorders in mice that are relevant to humans in the near future.

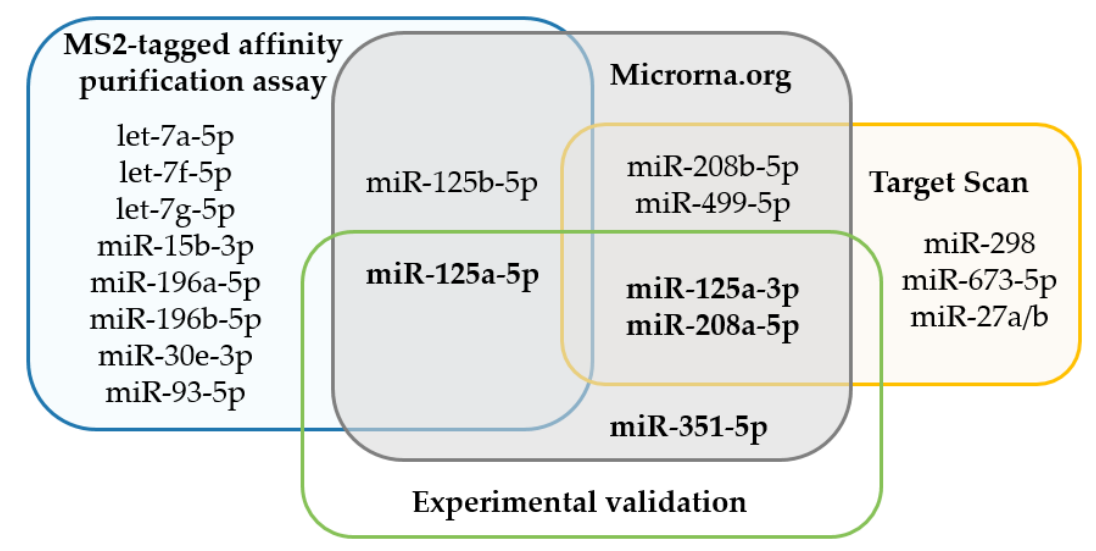

Figure 4. MiRNAs identified to target muF8 3'UTR. Venn diagram of microRNAs identified by MS2-taq affinity assay, predicted to target $F 83^{\prime}$ UTR by prediction algorithms (microrna.org, http://www.microrna. org), Target Scan and experimentally validated in vitro via luciferase assay and on MS1 cells.

Preclinical animal models that have been developed for HA (rats, dogs, sheep, and genetically engineered mice and pigs) are all focused towards developing appropriate therapies for HA [7] and thus carry a non-functional $F 8$ gene. Only recently have we shown that miRNAs can also influence the HA disease outcomes including in patients with normal $F 8$ gene; to our knowledge, there are no animal models to test this hypothesis. Since mice do not develop hemophilia [11], in the currently available mouse model HA for bleeding disorder, a part or whole $F 8$ gene is deleted $[8,20,21]$. As a result, the FVIII-deficient mice have no detectable circulating factor VIII. Hence, these mouse models cannot be used to study the miRNA-based regulation of $F 8$. Two transgenic mice models expressing a human FVIII variant with R593C mutation [22] and a human FIX variant with R333Q mutation [23] have been reported. However, these mice exhibit the hemophilia phenotype; i.e., the human-FVIII and human-FIX are non-functional. For models that evaluate whether microRNA mediated the control of FVIII (or FIX) expression, it is necessary that the wild-type fully functional FVIII proteins are expressed. These models can then be used to unequivocally determine whether (a) micro-RNAs can downregulate 
FVIII expression in vivo and (b) whether the downregulation of the $F 8$ gene is sufficient to elicit a hemophilia phenotype. In vivo evaluation of the effect of miRNAs on F8 gene expression (mRNA) and subsequent FVIII production can be performed by first injecting the selected miRNAs into the tail veins similar to antibody injections as reported [24], followed by using a variety of different assays, including the tail vein transection assay as well as more recently developed models of thrombosis and hemostasis [25-27]. The tail transection assay measures both venous and arterial bleeding [24]. Though yet to be experimentally verified, the simplicity of this envisioned mouse model for miRNA:F8 interactions should encourage scientists in the field to apply this approach to their research needs.

\section{Materials and Methods}

\subsection{Cell Culture}

The cell lines were obtained from ATCC. HEK293 cell lines (ATCC, CRL-11268) were maintained in Dulbecco's Modified Essential Medium (DMEM) with 10\% fetal bovine serum (FBS), $100 \mathrm{U} / \mathrm{mL}$ penicillin and $100 \mathrm{mg} / \mathrm{mL}$ streptomycin (Pen-Strep). HeLa cells (ATCC, CCL-2) were maintained in Minimum Essential Medium (MEM) with 10\% FBS, and Pen-Strep and MS1 (MILE SVEN 1) (ATCC, CRL-2279) cells were grown in DMEM with 5\% FBS, Pen-Strep.

\subsection{Plasmid Constructs}

Complementary DNA representing the 3'UTR of murine F8-mRNA was obtained from the liver of the $\mathrm{C} 3 \mathrm{H} / \mathrm{HeJ}$ mouse, amplified by RT-PCR (using primers: Mmu-F8-ECOR1-F: ATGCGAATTCacccccagatctgggagc and Mmu-F8-Not1-R: ATATGCGGCCGCaaactataag taagccetgattaaatgc) and cloned into Gaussia luciferase reporter plasmid pEZX-MT05. pEZX-MT05 and a plasmid, pEZX-MR04expressing precursor miRNA, along with a green fluorescent protein (eGFP) reporter gene, were both obtained from Genecopia Inc. MS2 and MS2-GST plasmids were a gift from Dr. Myriam Gorospe, NIA, NIH and described previously [13]. The murine F8 3'UTR fragment was cloned into MS2 plasmid (using primers: Mmu-F8-ECOR1-F: ATGCGAATTCacccccagatctgggagc and Mmu-F8-Not1-R: ATATGCGGCCGCaaactataagtaagccctgattaaatgc). HEK293 lines were transfected with the above vectors using the Lipofectamine 2000 transfection reagent (Invitrogen, Carlsbad, CA, USA) according to the manufacturer's protocol.

\subsection{Luciferase Assay}

For luciferase reporter assays, HEK293 and HeLa cells were co-transfected with pEZX-MT05 plasmid encoding the muF8 $3^{\prime}$-UTR and precursor miRNA expression plasmid to express desired miRNAs. In parallel, the cells were co-transfected with F8 $3^{\prime}$-UTR pEZX-MT05-plasmid and miRNA scrambled sequence control (SC) containing pEZX-MR04. Transfection was carried out using Lipofectamine 3000 (Invitrogen, Carlsbad, CA, USA). The reporter gene activities were measured 48 and $72 \mathrm{~h}$ after transfection by dual-luciferase assay-system (GeneCopoeia, Rockville, MD USA). A secreted Alkaline Phosphatase (SEAP) reporter driven by a CMV promoter cloned into the same plasmid served as an internal control and was used for normalizing the transfection efficiency. The data were presented as fold-change relative to the negative (scrambled) control. MiRNA overexpression in transfected cells was quantified by qPCR [5].

\subsection{MS2-Tagged RNA Affinity Purification (MS2-TRAP) and Identification of F8 3'UTR-Interacting miRNAs}

The MS2-TRAP assay was performed as described previously [11-13]. Briefly, MS2-tagged F8 3'UTR (test) plasmid or empty MS2 plasmid (control) along with a MS2-GST plasmid expressing MS2 coat protein and glutathione transferase as a fusion protein were expressed in HEK293 cells. After $48 \mathrm{~h}$, the harvested cells were lysed in NP-40 lysis buffer. Equal concentrations of clarified supernatants ( $2 \mathrm{mg} / \mathrm{mL}$ of lysates) were incubated with glutathione beads overnight at $4{ }^{\circ} \mathrm{C}$ to ensure binding of miRNAs to their target sequence present in the $F 83^{\prime} \mathrm{UTR}$. Finally, the RNAs bound to 
the beads were extracted using Trizol reagent method, as suggested by the manufacturer's protocol (Invitrogen, Carlsbad, CA, USA). RNA samples were analyzed in 2100 Agilent Bioanalyzer using the Small RNA kit (Agilent Technologies, Santa Clara, CA, USA) according to the manufacturer's instructions. All analyses were performed using the Agilent 2100 expert software. RNAs from the control and test plasmid-transfected HEK293 cells were subjected to next-generation sequencing (NGS) in our in-house core facility at FDA, using an Illumina small RNA kit to identify the miRNAs associated with the F8 $3^{\prime} \mathrm{UTR}$.

The NGS data were analyzed by using miRDeep2, one of the miRNA identification tools, and then aligned this information with the miRNA database, miRBase 21. The data output was sorted based on the total number of reads for each miRNA and their fold change in the test sample relative to the control. A threshold of 1.5 -fold change and read counts (read\#) $\geq 40$ was used to discriminate differences in the expression of miRNA. In addition, $p$-values from t-distributions were calculated for each miRNA with the assumption of standard deviation equal to 8 read counts and degrees of freedom $\mathrm{DF}=4$. A threshold of $p$-value $<0.05$ was used to discriminate between significant and insignificant differences in pulled-down miRNAs.

\subsection{Cell Transfection}

Mouse MILE SVEN 1 cells (MS1 line) that endogenously express FVIII protein [14] were transfected with miRNA expression vectors using Lipophetamine 3000 (Invitrogen, Carlsbad, CA, USA). After $72 \mathrm{~h}$, the cell pellet was collected and lysed either in Trizol reagent (for RNA expression studies by qPCR) or RIPA buffer (for protein expression studies by WB).

\section{6. $R T-q P C R$}

Total RNA from cell pellets was isolated using Trizol reagent, according to the manufacturer's instructions. To detect the relative levels of F8-mRNA and miRNAs, quantitative real time-PCR (qPCR) was performed. For $F 8$, the cDNA was generated with $1 \mu \mathrm{g}$ total RNA by reverse transcription using SuperScript III Reverse Transcriptase (Invitrogen, Carlsbad, CA, USA) and oligo (dT) primers.

PCR products were quantitatively synthesized from cDNA samples using the TaqMan Gene Expression Master Mix and TaqMan Gene Expression Assays specific to coagulation factor VIII (Mm01215675, Applied Biosystems, Foster City, CA, USA) and GAPDH (Mm99999915, Applied Biosystems, Foster City, CA, USA). GAPDH was used as an endogenous control. The reaction conditions were used as described in gene expression master mix protocol.

For mature miRNA quantification, cDNA was synthesized from total RNA samples using specific miRNA primers provided with the TaqMan MicroRNA Assay and reagents from a TaqMan microRNA reverse transcription kit. RNU6 small nuclear RNA was used as an internal control. TaqMan miRNA assays and RNU6 snRNA were from Applied Biosystems. In the PCR step, PCR products were amplified from cDNA samples using the TaqMan MicroRNA Assay together with the TaqMan Universal PCR master mix. The reaction conditions followed TaqMan MicroRNA Assays Protocol. The fold change for each target gene relative to the control group was calculated using the $\Delta \Delta \mathrm{Ct}$ method.

\subsection{Western Blot}

Pellets of MS2 cells collected 48h after transfection with miRNA expression vectors were lysed by sonication in RIPA buffer with addition of PMSF (phenylmethylsulfonyl fluoride) prior to lysis. Gel electrophoresis (4-15\% gradient gel) of lysates was followed by transfer to nitrocellulose membranes using Trans-Blot Turbo system (BioRad, Hercules, CA, USA). Blots were blocked with 5\% skim milk in TPBS buffer (PBS buffer with Tween 20), incubated overnight with an anti-FVIII antibody (Abcam ab53703, 1:1000) followed by incubation with a secondary antibody, goat anti-Rabbit IgG, 1:10,000 (Invitrogen, Carlsbad, CA, USA) conjugated to horseradish peroxidase (HRP). Following development, blots were imaged and analyzed using an Image Station 4000MM PRO (Carestream, Rochester, NY, USA). 


\subsection{Data Analysis}

Statistical analysis was performed using Microsoft Excel and Prism software. Unless otherwise indicated, statistical significance was calculated using Student's T-test for unpaired samples, and data are presented as mean $+/-$ Standard Error.

Supplementary Materials: Supplementary materials can be found at http://www.mdpi.com/1422-0067/21/16/ 5621/s1.

Author Contributions: K.I.J. helped in the design of the study, performed experiments, data analyses and participated in writing of the manuscript. M.C. participated in miRNA prediction analyses, designing the research plan and helped in plasmids cloning. Z.E.S., M.C. and C.D.A. designed the research plan. oversaw the project and wrote the manuscript. All authors have read and agreed to the published version of the manuscript.

Funding: This work was supported by FDA intramural research funds. K.I.J. and M.C. are recipients of Oak Ridge Institute for Science and Engineering fellowship.

Acknowledgments: This project was supported by appointment to the Research Participation Program (K.I.J.) at the Office of Blood Research and Review and the Office of Tissues and Advanced Therapies, Center for Biologics Evaluation and Research, US Food and Drug Administration, administered by the Oak Ridge Institute for Science and Education through an interagency agreement between the US Department of Energy and the FDA.

Conflicts of Interest: The authors declare no conflict of interest.

\section{Abbreviations}

$\begin{array}{ll}\text { DF } & \text { Degrees of freedom DF } \\ \text { F8 } & \text { gene encodes coagulation factor VIII } \\ \text { FVIII } & \text { coagulation factor VIII } \\ \text { GAPDH } & \text { Glyceraldehyde 3-phosphate dehydrogenase } \\ \text { HEK293T } & \text { Human embryonic kidney 293 cells } \\ \text { HeLa } & \text { Human immortal cell line derived from cervical cancer cells } \\ \text { HRP } & \text { horseradish peroxidase } \\ \text { miRNA } & \text { micro RNA } \\ \text { mmu } & \text { Mus musculus (mouse) } \\ \text { muF8 } & \text { Murine F8 } \\ \text { MS1 } & \text { MILE SVEN 1 cells } \\ \text { MS2 } & \text { MS2 plasmid } \\ \text { MS2-E } & \text { MS2 vector-empty, negative control } \\ \text { MS2-muF8 } & \text { MS2 vector fused to the 3'UTR of murine F8 } \\ \text { MS2-TRAP } & \text { MS2-tagged affinity assay } \\ \text { NSG } & \text { Next generation sequencing } \\ \text { qPCR } & \text { Quantitative polymerase chain reaction } \\ \text { TPBS } & \text { Phosphate-buffered saline buffer with Tween 20 } \\ \text { UTR } & \text { Untranslated region }\end{array}$

\section{References}

1. Orlova, N.A.; Kovnir, S.V.; Vorobiev, I.I.; Gabibov, A.G.; Vorobiev, A.I. Blood Clotting Factor VIII: From Evolution to Therapy. Acta Nat. 2013, 5, 19-39. [CrossRef]

2. Johnsen, J.M.; Fletcher, S.N.; Huston, H.; Roberge, S.; Martin, B.K.; Kircher, M.; Josephson, N.C.; Shendure, J.; Ruuska, S.; Koerper, M.A.; et al. Novel approach to genetic analysis and results in 3000 hemophilia patients enrolled in the My Life, Our Future initiative. Blood Adv. 2017, 1, 824-834. [CrossRef] [PubMed]

3. El-Maarri, O.; Herbiniaux, U.; Graw, J.; Schroder, J.; Terzic, A.; Watzka, M.; Brackmann, H.H.; Schramm, W.; Hanfland, P.; Schwaab, R.; et al. Analysis of mRNA in hemophilia A patients with undetectable mutations reveals normal splicing in the factor VIII gene. J. Thromb. Haemost. 2005, 3, 332-339. [CrossRef] [PubMed]

4. Sarachana, T.; Dahiya, N.; Simhadri, V.L.; Pandey, G.S.; Saini, S.; Guelcher, C.; Guerrera, M.F.; Kimchi-Sarfaty, C.; Sauna, Z.E.; Atreya, C.D. Small ncRNA Expression-Profiling of Blood from Hemophilia A Patients Identifies miR-1246 as a Potential Regulator of Factor 8 Gene. PLoS ONE 2015, 10, e0132433. [CrossRef] [PubMed] 
5. Jankowska, K.I.; McGill, J.; Pezeshkpoor, B.; Oldenburg, J.; Atreya, C.D.; Sauna, Z.E. Clinical manifestation of hemophilia A in the absence of mutations in the F8 gene that encodes FVIII: Role of microRNAs. Transfusion 2020, 60, 401-413. [CrossRef]

6. Selvaraj, S.R.; Pipe, S.W. Not in the genotype: Can unexplained hemophilia A result from "micro (RNA) management"? Transfusion 2020, 60, 227-228. [CrossRef]

7. Sun, T.; Li, M.Y.; Li, P.F.; Cao, J.M. MicroRNAs in Cardiac Autophagy: Small Molecules and Big Role. Cells 2018, 7, 104. [CrossRef]

8. Yen, C.T.; Fan, M.N.; Yang, Y.L.; Chou, S.C.; Yu, I.S.; Lin, S.W. Current animal models of hemophilia: The state of the art. Thromb. J. 2016, 14, 22. [CrossRef] [PubMed]

9. Lenting, P.J.; Van Mourik, J.A.; Mertens, K. The life cycle of coagulation factor VIII in view of its structure and function. Blood 1998, 92, 3983-3996. [CrossRef]

10. Chao, B.N.; Baldwin, W.H.; Healey, J.F.; Parker, E.T.; Shafer-Weaver, K.; Cox, C.; Jiang, P.; Kanellopoulou, C.; Lollar, P.; Meeks, S.L.; et al. Characterization of a genetically engineered mouse model of hemophilia A with complete deletion of the F8 gene. J. Thromb. Haemost. 2016, 14, 346-355. [CrossRef]

11. Sabatino, D.E.; Nichols, T.C.; Merricks, E.; Bellinger, D.A.; Herzog, R.W.; Monahan, P.E. Animal models of hemophilia. Prog. Mol. Biol. Transl. Sci. 2012, 105, 151-209. [CrossRef] [PubMed]

12. Yoon, J.H.; Gorospe, M. Identification of mRNA-Interacting Factors by MS2-TRAP (MS2-Tagged RNA Affinity Purification). Methods Mol. Biol. 2016, 1421, 15-22. [CrossRef] [PubMed]

13. Yoon, J.H.; Srikantan, S.; Gorospe, M. MS2-TRAP (MS2-tagged RNA affinity purification): Tagging RNA to identify associated miRNAs. Methods 2012, 58, 81-87. [CrossRef]

14. Dahiya, N.; Atreya, C.D. RAP1 Downregulation by miR-320c Reduces Platelet Activation in Ex-vivo Storage. Microrna 2019, 8, 36-42. [CrossRef] [PubMed]

15. Kumaran, V.; Benten, D.; Follenzi, A.; Joseph, B.; Sarkar, R.; Gupta, S. Transplantation of endothelial cells corrects the phenotype in hemophilia A mice. J. Thromb. Haemost. 2005, 3, 2022-2031. [CrossRef] [PubMed]

16. Nourse, J.; Braun, J.; Lackner, K.; Huttelmaier, S.; Danckwardt, S. Large-scale identification of functional microRNA targeting reveals cooperative regulation of the hemostatic system. J. Thromb. Haemost. 2018, 16, 2233-2245. [CrossRef]

17. Wang, X.; Sundquist, K.; Svensson, P.J.; Rastkhani, H.; Palmer, K.; Memon, A.A.; Sundquist, J.; Zöller, B. Association of recurrent venous thromboembolism and circulating microRNAs. Clin. Epigenet. 2019, 11, 28. [CrossRef]

18. Teruel, R.; Corral, J.; Perez-Andreu, V.; Martinez-Martinez, I.; Vicente, V.; Martinez, C. Potential role of miRNAs in developmental haemostasis. PLoS ONE 2011, 6, e17648. [CrossRef]

19. Jankowska, K.I.; Sauna, Z.E.; Atreya, C.D. Role of microRNAs in Hemophilia and Thrombosis in Humans. Int. J. Mol. Sci. 2020, 21, 3598. [CrossRef] [PubMed]

20. Lozier, J.N.; Nichols, T.C. Animal models of hemophilia and related bleeding disorders. Semin. Hematol. 2013, 50, 175-184. [CrossRef]

21. Monahan, P.E. The expanding menagerie: Animal models of hemophilia A. J. Thromb. Haemost. 2010, 8, 2469-2471. [CrossRef]

22. Bril, W.S.; Van Helden, P.M.W.; Hausl, C.; Zuurveld, M.G.; Ahmad, R.U.; Hollestelle, M.J.; Reitsma, P.H.; Fijnvandraat, K.; Van Lier, R.A.W.; Schwarz, H.P.; et al. Tolerance to factor VIII in a transgenic mouse expressing human factor VIII cDNA carrying an Arg(593) to Cys substitution. Thromb. Haemost. 2006, 95, 341-347.

23. Jin, D.-Y.; Zhang, T.-P.; Gui, T.; Stafford, D.W.; Monahan, P.E. Creation of a mouse expressing defective human factor IX. Blood 2004, 104, 1733-1739. [CrossRef] [PubMed]

24. Meeks, S.L.; Healey, J.F.; Parker, E.T.; Barrow, R.T.; Lollar, P. Non-classical anti-factor VIII C2 domain antibodies are pathogenic in a murine in vivo bleeding model. J. Thromb. Haemost. 2009, 7, 658-664. [CrossRef] [PubMed]

25. Furie, B.; Furie, B.C. In vivo thrombus formation. J. Thromb. Haemost. 2007, 5, 12-17. [CrossRef] [PubMed]

26. Sachs, U.J.; Nieswandt, B. In vivo thrombus formation in murine models. Circ. Res. 2007, 100, 979-991. [CrossRef] [PubMed]

27. Broze, G.J.; Yin, Z.F., Jr.; Lasky, N. A tail vein bleeding time model and delayed bleeding in hemophiliac mice. Thromb. Haemost. 2001, 85, 747-748.

(C) 2020 by the authors. Licensee MDPI, Basel, Switzerland. This article is an open access article distributed under the terms and conditions of the Creative Commons Attribution (CC BY) license (http://creativecommons.org/licenses/by/4.0/). 